\title{
Protocol for Conducting Procedural Skills Training With Simulators: A Critical Proposal
}

\author{
Gleyvis Coro-Montanet, $\mathrm{PhD}$ \\ Universidad Europea, Madrid, Spain \\ (iD) https://orcid.org/0000-0002-0009-1710
}

Julia Sánchez-Ituarte, PhDc

Universidad Europea, Madrid, Spain

(iD https://orcid.org/o0oo-0002-3932-9183

Ana de la Hoz-Calvo, $\mathrm{PhD}$

Universidad Europea, Madrid, Spain

(iD https://orcid.org/0000-0003-4163-714X

María Jesús Pardo-Monedero, $\mathrm{PhD}$

Universidad Europea, Madrid, Spain

(iD https://orcid.org/0000-0001-6884-2309

Contact: gleyvis.coro@universidadeuropea.es

\begin{abstract}
Task trainer simulators are often used in medical programs for bachelor's degree students when teaching procedural skills. They provide the opportunity to practice dangerous maneuvers that students are not ready to perform on real patients yet. The rise of technology has vastly expanded the availability of these devices for use in teaching. To develop a protocol that would account for the complexities of psychomotor learning, based on student progress, and improve training quality, we designed a protocol for the bachelor's degree program in dentistry. We justify the key elements of the proposal and explain the full working protocol.
\end{abstract}

Keywords: task simulator; procedural skills training; psychomotor domain

Submitted: September 6, 2020 | Accepted: March 7, 2021 | Published: April 26, 2021

Recommended Citation

Coro-Montanet G., Sánchez-Ituarte, G., de la Hoz-Calvo, A., \& Pardo-Monedero, M. J. (2021). Protocol for conducting procedural skills training with simulators: A critical proposal. Higher Learning Research Communications, 11(1) 1-13. https://doi.org/10.18870/hlrc.v1111.1210

\section{Introduction}

Procedural skills training develops students' visual, manual, and sensory memory. These activities promote patient safety when linked to a task simulator, allowing students to train without harming the patient (Foley \& Smilansky, 1980). In medical education, skills training involves performing a repetitive action in a controlled, 
goal-oriented environment (Darzi et al., 1999). If these learning processes are not properly managed by instructors, achieving a skill may be delayed or acquiring expertise may be hindered (Stefanidis et al., 2017).

Many instructors accumulate knowledge and experience by working in a clinical environment for several years. They are not familiar, however, with the methodological approaches needed to convey their personal experiences. These methodological approaches include adequate feedback and monitoring each student's progress (Cooper \& Taqueti, 2008; Harrow, 1972; Lenchus, 2010).

The proliferation of different devices in the high-fidelity task simulator market has changed the way we train. The new designs enhance the "wow effect"; prices are becoming more competitive, and the availability of spare parts extends the useful life of the simulators (Stefanidis et al., 2017). Moreover, the boom of digital worlds and extended realities make this alternative increasingly applicable. However, it is often mistakenly believed that acquiring a simulator automatically leads to better learning.

We should not forget that training is not merely the completion of purely manual exercises (Gallagher et al., 2005; Singer, 1972). Using this idea as a basis, we designed a protocol for conducting training workshops that develop complex psychomotor skills.

\section{Review of Didactic Theories on Psychomotor Learning}

Over the years, different teaching theories have been published on psychomotor learning, all of which look for the best learning outcome. According to Fitts and Posner (1967), the first phase of motor learning corresponds to a cognitive stage. During this phase, students face an excess of unknown tasks that they need to assimilate. Therefore, they must create their own performance patterns, supported by instructor guidance and feedback, and learn by trial and error. This cognitive stage gives way to the association phase. During the association phase, students perfect the execution of tasks and improve synchronization and automation. They become better at detecting their own mistakes and no longer rely as much on instructor indications (Fitts \& Posner, 1967). When explained in this way, it seems simple and fast. However, the transition to autonomy, a stage where cognitive effort is minimal (Schmidt et al., 2018), is a complex process that is often delayed and undermined. Instructors may not have the knowledge to understand and attend to student progress.

Burch (1970) described several stages of motor learning. The first one is an unconscious stage of incompetence, in which students do not realize they do not know how to do it. In the following stages, students become aware of their incompetence. Later, they acquire competence, although they require great concentration to act. In the final stage, they achieve an unconscious competence in which they assimilate the skills and perform them naturally and with ease.

Dave (1970) established five phases for the acquisition of advanced psychomotor skills: imitation, manipulation, precision, articulation, and naturalization. He proposed phase-specific psychomotor goals. His model is easily applicable in fine psychomotor skills training. In modern medical schools, however, traditional models applied to the training of these fine psychomotor skills are often associated with another, simpler, two-stage method. In it, the instructor briefly explains and executes the activity, and then the student reproduces it.

Another model often used in the revised academic fields is the four-stage alternative model described by Peyton (1998). The four stages include demonstration without comments from the instructor, breaking down the skill into stages or steps, comprehension of the skill acquired by describing the steps, and finally, execution by the student. Simultaneously, instructors can provide real-time feedback (Lorenzo \& PorrasGallo, 2016). 
Ericsson (2004) put forth the deliberate practice model with four components of setting concrete goals, repetition, feedback from instructors, and training in a motivating environment. He raised the need for an average of 10 years of training, or 10,000 hours, for the transition from apprentice to expert. According to his theory, stage deconstruction and routine would turn apprentices into experts, regardless of their personal variability. The scientific community focused its criticisms on this automated approach, claiming that Ericsson neglected the intrinsic characteristics of apprentices. Few noticed, however, that the emotional component-the presence of a motivating environment Ericsson introduced into its formula-was perhaps the most progressive element of teaching customization in a long time.

\section{Designing and Validating the Training Protocol for Procedural Skills}

To design the protocol, we carried out a systematic search focused on psychomotor domain, procedure training, and task training. This search was carried out to identify good practices and taxonomies and theories of psychomotor learning and to link them to learning strategies based on clinical simulation. The inclusion criteria for the articles and taxonomies examined included experiences that had more than 10 years of application and more than 100 citations with a high impact factor.

After analyzing didactic and practical theories that had the greatest impact on learning fine and gross psychomotor skills, we selected the most favorable elements of each. The three main methodological phases of the protocol presented in this article were then defined:

1. Briefing: This involves collecting information about the task to be performed. This can be done several days or weeks in advance or immediately before the task.

2. Skill Development: During this phase, trainees execute a skill using a simulator.

3. Feeds: Feeds provide information about the gap between the students' expected level and actual level. It aims to take students out of their comfort zone and encourage performing more complex actions.

For a more detailed application of this third phase, it was considered necessary to include three types of support:

1. Real-time feedback: This is the professor's information about the gap between what the students have done and what should be done, according to a reference model previously established by the teaching team. This feedback indicates an evaluation of both the final product and the process carried out.

2. Feedforward: This indicates what the students should improve upon for the future. This evaluation and information exchange is done in pairs or small groups of students with the teacher's guidance and involves an analysis for improvement.

3. Feedwithin: Feedwithin includes the "tricks," tips, or skills discovered by the students themselves. The students discover and share these actions, and this can be encouraged by the teacher throughout the activity and at the end of the activity.

In addition to considering the different models of motor learning and student progress, the protocol followed the principles of technological integration of modern simulators using the TPACK (Technological Pedagogical Content Knowledge) method developed by Harris and Hofer (2009) and simulation-based learning (Motola et al., 2013).

The protocol was then applied in skill workshops at the university between September 2016 and November 2019. Implementation occurred during complex procedure training in the undergraduate dentistry curriculum 
in the subjects of pediatric dentistry, restorative dentistry, biomaterials, and prosthetics (Coro-Montanet et al., 2017). The instructors, comprising 14 teachers with more than 5 years of teaching experience each, were present at all times.

A total of 2,967 cavity preparation exercises were performed on virtual teeth with Simodont $\AA$ dental training simulators (Figure 1). The Simodont dental simulator is a state-of-the-art technological simulator. It combines three interfaces: a haptic field, a 2D touch screen, and a 3D dental model viewer for training gross and fine motor skills (Murbay et al., 2020; Zafar et al., 2020).

Figure 1: Preclinical Education Procedures for Virtual Tooth Drilling with Simodont ${ }^{\circledR}$

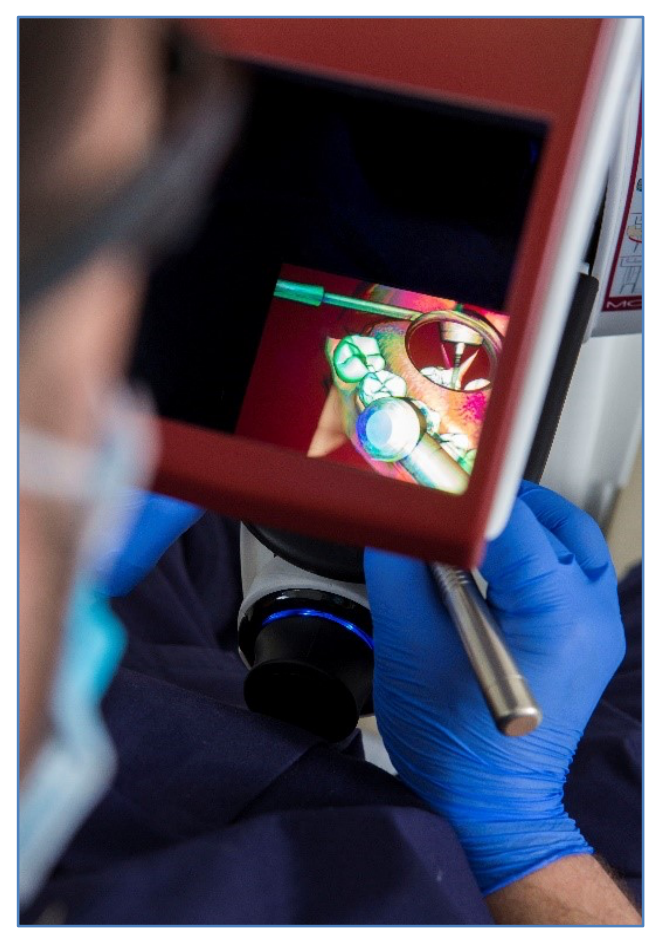

Source: Authors

\section{Description of the Training Protocol for Procedural kills}

The protocol consists of three general parts: preworkshop briefing, skill development (learning by doing), and evaluation. The protocol begins with a pre-exercise briefing that includes two modalities-prior briefing and immediate briefing. When it comes to complex tasks that involve surpassing various difficulties to achieve goals, complex simulators, or environments with advanced technology, the prior briefing is done days or weeks in advance. A pretest is also included during which the students show whether they have acquired the necessary knowledge to carry out the activity. For simple exercises with low cognitive load, prior briefing may not be necessary. Students would begin directly with the immediate briefing for the skill. It provides enough information to familiarize them with the environment, simulators, and content. The differentiation between these two types of briefings was based on the ideas of Cognitive Load Theory (Young et al., 2014). Once this first phase is over, students move on to immediate briefing, which takes place minutes before the exercise.

The exercise is based on the active learning ideas reviewed in the previously selected taxonomies. The student performs the skill repeatedly and shows progress that the instructor can follow at all times and support with expert feedback. In this exercise, the instructor uses a checklist to assess student progress objectively. This 
checklist allows the teacher to guide student learning, indicating what should be improved in that moment (real-time feedback) and in future exercises (feedforward). Instructors also rely on group intelligence (the contribution of other students' learning) to close the loop of meaningful team learning.

Figure 2 shows the process that this new protocol follows, starting with the briefings and ending with the correct execution of the skill thanks to the students' progress. For each phase of the protocol, a teaching objective and strategy were established. The protocol was highly useful, as there were not many guidelines available to use as a basis for designing and implementing these teaching models.

Figure 2: Training Model for Teaching Procedural Skills

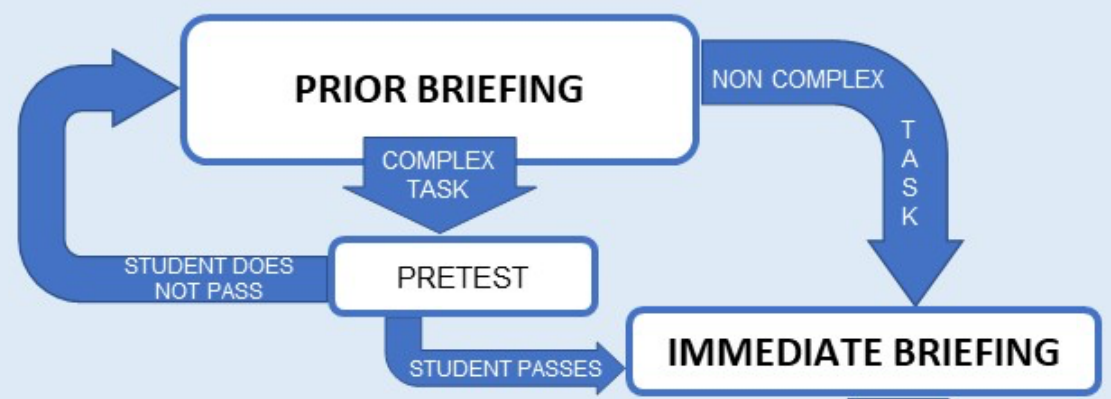

\section{LEARNING BY DOING}
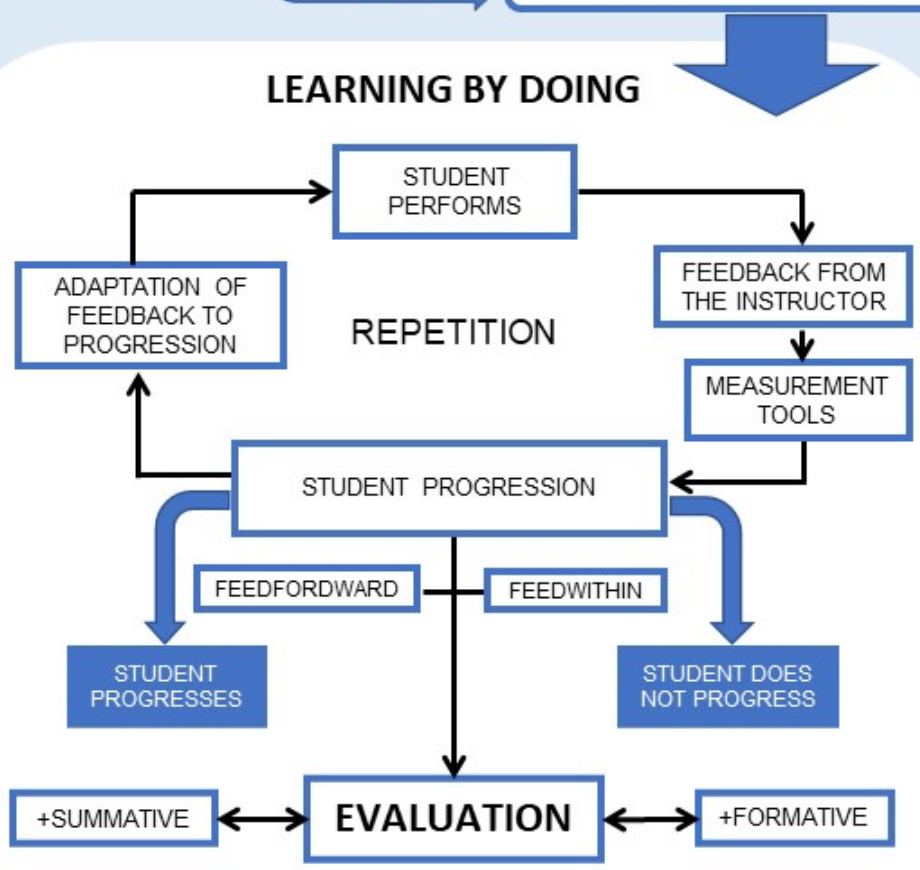


\section{Principal parts of the protocol}

Prior briefing. Prior briefing established the theoretical and psychomotor pattern for the skill. Its purpose was to describe how to perform the skill and how to handle the task trainer and the environment (classroom or laboratory). This was achieved through the use of audiovisual and graphic resources. Briefings were designed around the idea that raising the level of students' prior knowledge would decrease cognitive effort during the exercise (Clapper \& Kardong-Edgren, 2012; Gallagher et al., 2005; Leigh \& Steuben, 2018). Providing cognitive elements in advance encourages students to accept more ambitious psychomotor challenges later during the exercise (George et al., 2019). Prior briefing helps the students gain motivation and create skill models before performing the task. When the skill is complex or the students have limited experience, this instruction is especially helpful.

The lack of documentation or specific literature on how to perform the skill demonstration was evident in the study of traditional models on psychomotor learning. There was theoretical literature on the dental treatments but little detailed explanation of how to perform the skills necessary to do those treatments. In the simulations, we eliminated this gap by including documents prepared by instructors and experts with precise instructions on what students needed to achieve in terms of psychomotor skills and how to perform the simulation. The materials gave an in-depth explanation of the steps to follow and the purpose of each one.

It should be noted that, for very complex skill development, providing prior documentation might be insufficient. In such cases, it is recommended that students have prior exposure to the simulators so that they can become familiar with the environment before performing the activity.

Pretest. A pretest was determined to be necessary. Students must pass the pretest to access the skill development workshop. If students do not have a minimum knowledge, their individual practice is wasted and, in addition, it usually negatively influences the performance of the group when the exercise is done in groups or couples (Anton et al., 2016). Students who did not pass the pretest would go on to do a different activity. Likewise, a rule was established that those students should undergo a new evaluation until they could demonstrate that their cognitive level was sufficient to perform the task and work with a complex simulator.

This pretest serves as a way to measure students' knowledge deficit, which is also a psychomotor deficit; it serves as the students' first form of feedback. When a significant number of students do not pass the pretest, this indicates the need to reformulate the briefing or include a preliminary immersive activity in the briefing that allows students to become familiar with simulators and environments, as is done in very complex workshops.

Immediate briefing. Once pretesting is complete, the students attend the skill development workshop where they are given an immediate briefing. The main objective of the immediate briefing is to reinforce key concepts, both theoretical and psychomotor, in the workshop. To do this, we also use graphic and audiovisual resources that are complemented with an in situ demonstration by the instructor or with a prerecorded demonstration with comments.

In skill development workshops with more complex learning goals, the instructor performs a prior demonstration of the skill at different speeds as part of the immediate briefing; sometimes the instruction is verbal and sometimes students are encouraged to provide their own feedback. Emphasis is placed on the most critical aspects of the skill, which are those core concepts and actions the students should know and be able to perform.

Skill development. Teachers always follow specific guidelines to assess student progress at different phases of autonomous skill development in terms of what is expected of the students in each phase and what the teacher should do. 
- Imitation phase: The students develop simple imitation skills. The instructor promotes repetition of the exercise, offering constant feedback with very simple evaluation tools. Feedback at this stage is both from the final result (of the product) and from the process carried out.

- Manipulation phase: The students begin to associate and reproduce, through repetition, the skill reference model. The instructor promotes learning by providing constant feedback on simple activities. Evaluation items will remain simple, geared toward psychomotor skills that do not include other activities.

- Precision phase: The students begin to automate the skill, reproducing the reference pattern in more detail. The instructor encourages learning by allowing the students to integrate various skills while offering feedback only if it is truly necessary.

- Articulation phase: The students perform increasingly complex skills, introducing their own psychomotor patterns and improving speed. At this stage, feedback is scarce and measurement tools should be more rigorous.

- Naturalization phase: The students perform complex skills with precision and expertise while developing their own psychomotor model. At this stage, the instructor will only provide product feedback (at the end of the process) using measurement tools with rigorous criteria.

- Evaluation phase: The instructor will use feedforward and feedwithin to encourage discussions among the students and their group. Through a constructive conversation that includes improvements for the next activity, the instructor will encourage formative and summary evaluation.

Evaluation. The most used measurement tool in this protocol was the checklist, which some authors elevate to the category of structured protocols (Lorenzo \& Porras-Gallo, 2016). Checklists are true cognitive aids for students as well as assessment references for instructors (Clapper \& Kardong-Edgren, 2012). An exhaustive checklist should describe the objectives for the different phases of the student progression found at the skill development (Ramaprasad, 1983). Elements or descriptors break down the activities to be performed and must be sorted according to the execution sequence. The degree of specificity and depth of each descriptor will depend on the objectives and progress of the students. The more the students progress, the more detailed and demanding the items can be (Fann et al., 2012).

For the information provided by the instructor to be complete, there must be input, processing, and output feedback. All feedback must be adapted to a quantitative measurement (Ramaprasad, 1979). It is not about turning qualitative opinion into a quantitative parameter, however; this can lead to a serious failure of communication between the students and the instructor (Jensen et al., 2012; Shute, 2008).

Neither reproach nor praise constitutes feedback. Training is complete when the information provided by the instructor is used by students to reduce their learning deficit (Bogart, 1980; Reiley et al., 2011). That is, only when students have honed their learning awareness will the information provided by the teacher become feedback and stop being mere commentary.

The most recent research suggests that group feedback and debriefing strategies are the key final element in the cycle of meaningful information communication (Basso \& Belardinelli, 2006; Rae \& Cochrane, 2008; García-San Pedro, 2012). As such, all skill development workshops should conclude with educational reflections that include teacher assessment, peer assessment, and self-assessment (in Spanish, heteroevaluación), which allow the students to see the progression of their skills as well as develop an action plan based on the changes and improvements they may need to make. 
We agree with Bogart (1980) on the need to consider the use of alternative mechanisms to feedback not exclusive to the instructor, such as feedforward and feedwithin. Feedforward is the prospective judgment in which the instructor continues to play a leading role, while feedwithin comes from the group intelligence that provides strategies, actions, and tricks discovered by the students themselves. Both feedforward and feedwithin may reveal important aspects of the group learning processes from which instructors themselves can benefit. Qualitative evaluation will be better suited for students who show less progress, whereas quantitative assessment will be better suited for rapidly progressing students. Table 1 summarizes the objectives and teaching strategies at each phase of the protocol for procedural skills.

\section{Linking Stages of Psychomotor Development With Individual Student Progress}

One of the major drawbacks of implementing any learning protocol is not being able to adapt it to the individual learning speed of each student. Therefore, this protocol focuses both on identifying the learning process of each individual and guiding the students through their formative journey.

In Dave's early stages (1970) of imitation, manipulation, and precision, proposing overly complex tasks is not suitable for inexperienced students, as they will not be able to assimilate them. Ericsson's principle of repetition (Ericsson, 2004) becomes relevant in these early stages. Performing tasks will take longer, so the student should not rush. Speed here is not necessary. And if several days of training are needed, they must be taken into account and scheduled.

In the articulation phase, students can now combine two or more skills and create their own execution models because they will feel cognitively freer and have more flexibility to create. In the naturalization phase, students perform consistently and with ease while perfecting their own model. They can integrate multiple tasks and may be asked to perform them in a shorter period to increase their speed (Arora et al., 2011).

Complex learning goals, which are complex tasks in and of themselves or tasks undertaken by students with little or no learning experience, must be deconstructed or broken down into phases. This will allow for fewer and simpler training objectives (Ericsson, 2004) while creating as many new performance phases as needed. It is crucial that the instructor does not forget that the pace of student automation varies depending on individual skills. Because of this variation, it is difficult to accurately establish how many repetitions or how long it takes to achieve automation for individual skills (Bonrath et al., 2015; Gallagher et al., 2005).

This protocol is limited in that it was implemented in skill workshops with haptic and three-dimensional simulators that, due to large digital display, allow instructors to more easily supervise students and be more aware of their progress. It is important, therefore, to apply it to larger samples and traditional exercises to multiply their benefits and implement possible improvements.

\section{Conclusions}

Training in simulator-based procedural techniques has become more common in medical degrees thanks to technological developments. It is necessary to create teaching protocols that allow instructors to be attentive to the students' initial cognitive status and subsequent progress and to guide them throughout their training and learning process. Instructors rely on various evaluation strategies to avoid leaving students to their own devices during the automation process of complex tasks. This is of the utmost importance because it enables students to treat future patients without causing them harm. 
Table 1: Objectives and Teaching Strategies at Each Phase of the Protocol of Procedural Skills

\begin{tabular}{|c|c|c|}
\hline Protocol phase & Purpose/goal & Teaching strategies \\
\hline $\begin{array}{l}\text { Prior briefing } \\
\text { (days or weeks } \\
\text { before the } \\
\text { activity) }\end{array}$ & $\begin{array}{l}\text { 1. Present the theoretical basis of a skill reference } \\
\text { model, agreed by the teaching team. This must be } \\
\text { mentally assimilated by the students prior to } \\
\text { practical execution. } \\
\text { 2. Help students have clear and solid understanding } \\
\text { of the procedure to be performed. }\end{array}$ & $\begin{array}{l}\text { Prior information will be provided in the appropriate } \\
\text { formats and media (texts, infographics, videos). This } \\
\text { documentation will show the theoretical approach to the } \\
\text { skill. } \\
\text { - Pretest will be conducted to determine the students' level } \\
\text { of knowledge and what motivates them to study. } \\
\text { - If theoretical strategies are not sufficient, familiarization } \\
\text { visits to simulation environments can be arranged. }\end{array}$ \\
\hline $\begin{array}{l}\text { Immediate } \\
\text { briefing } \\
\text { (minutes before } \\
\text { the activity) }\end{array}$ & $\begin{array}{l}\text { 3. Show and demonstrate the skill reference model. } \\
\text { 4. Try to help students assimilate the skill reference } \\
\text { model. } \\
\text { 5. Try to help students understand in what areas } \\
\text { they are still lacking. } \\
\text { 6. Report on workshop organization. }\end{array}$ & $\begin{array}{l}\text { - An in situ demonstration of the procedure will take place. } \\
\text { Graphic, audiovisual, or digital tools can be used to provide } \\
\text { students with the best possible demonstration on the } \\
\text { reference pattern of the skill. } \\
\text { - } \quad \text { The different execution speeds will be handled during the } \\
\text { demonstration. } \\
\text { - } \text { A combination of exercises (by the instructor, by students) } \\
\text { - } \quad \text { Thith or without comments may be performed. } \\
\text { - } \quad \text { The number of students per session and per instructor will } \\
\text { be specified. } \\
\text { - } \quad \text { Theviously tested run-times will be assigned. }\end{array}$ \\
\hline $\begin{array}{l}\text { Skill development } \\
\text { in the imitation } \\
\text { phase }\end{array}$ & $\begin{array}{l}\text { 7. Encourage students' performance of simple skills. } \\
\text { 8. Encourage students' imitation of the skill } \\
\text { reference model. } \\
\text { 9. Promote repetition. }\end{array}$ & $\begin{array}{l}\text { - The use of feedback is introduced on a consistent and } \\
\text { continuous basis. } \\
\text { Checklists will be used with items that verify simple, } \\
\text { unintegrated, and disaggregated actions. }\end{array}$ \\
\hline $\begin{array}{l}\text { Skill development } \\
\text { in the } \\
\text { manipulation } \\
\text { phase }\end{array}$ & $\begin{array}{l}\text { 10. Verify that the students have entered the } \\
\text { cognitive/motor association phase and recognize } \\
\text { what they are learning to do (conscious expertise). } \\
\text { 11. Encourage the students to reproduce the skill } \\
\text { reference model more fluidly. }\end{array}$ & $\begin{array}{l}\text { Process feedback will be given, adapted to progress. This } \\
\text { will be consistent and continuous. } \\
\text { Checklists will be used with items sorted by execution } \\
\text { sequence. Checklist items verify simple, low-detail, and } \\
\text { unintegrated actions. }\end{array}$ \\
\hline
\end{tabular}




\begin{tabular}{|c|c|c|}
\hline & 12. Promote repetition. & \\
\hline $\begin{array}{l}\text { Skills } \\
\text { development in } \\
\text { the precision } \\
\text { phase }\end{array}$ & $\begin{array}{l}\text { 13. Encourage the students to start the automation } \\
\text { phase (unconscious expertise). } \\
\text { 14. Encourage the students to expertly reproduce the } \\
\text { skill reference model. }\end{array}$ & $\begin{array}{l}\text { Process and product feedback will be given, adapted to } \\
\text { progress. This feedback and supervision will no longer be } \\
\text { constant. } \\
\text { - Checklists with more detailed and demanding items will be } \\
\text { used. Some simple skills can be included. }\end{array}$ \\
\hline $\begin{array}{l}\text { Skill development } \\
\text { in the articulation } \\
\text { phase }\end{array}$ & $\begin{array}{l}\text { 15. Encourage performing complex skills. } \\
\text { 16. Encourage the students to create their own } \\
\text { psychomotor models. } \\
\text { 17. Promote experience and speed. }\end{array}$ & $\begin{array}{l}\text { - Process feedback will be given, adapted to progress. This } \\
\text { feedback and supervision will no longer be constant. } \\
\text { - Checklists will be used where items verify performance in a } \\
\text { detailed manner and allow for the integration of simple } \\
\text { skills. }\end{array}$ \\
\hline $\begin{array}{l}\text { Skill development } \\
\text { in the } \\
\text { naturalization } \\
\text { phase }\end{array}$ & $\begin{array}{l}\text { 18. Develop integration at the level of unconscious } \\
\text { expertise, automation, and autonomy; students } \\
\text { must know how to do it with ease. } \\
\text { 19. Continue to encourage the students to create their } \\
\text { own models. } \\
\text { 20. Promote excellence. }\end{array}$ & $\begin{array}{l}\text { - Product feedback will be given. This type of feedback and } \\
\text { - } \quad \text { Checkervision does not need to be constant. } \\
\text { and complex actions. }\end{array}$ \\
\hline Evaluation & $\begin{array}{l}\text { 21. Promote the students'-and the group's- } \\
\text { understanding of key concepts about their } \\
\text { learning. } \\
\text { 22. Verify the students' understanding of key } \\
\text { concepts about their learning and progress, } \\
\text { oriented toward improvement. }\end{array}$ & $\begin{array}{l}\text { - Key concepts will be shared through output feedback + } \\
\text { checklists or rubrics. } \\
\text { - } \quad \text { The student/group perspective will be shared through } \\
\text { feedforward. } \\
\text { - Feedwithin will be used more frequently. }\end{array}$ \\
\hline
\end{tabular}




\section{References}

Anton, N. E., Howley, L. D., Pimentel, M., Davis, C. K., Brown, C., \& Stefanidis, D. (2016). Effectiveness of a mental skills curriculum to reduce novices' stress. Journal of Surgical Research, 206(1), 199-205. https://doi.org/10.1016/j.jss.2016.07.019

Arora, S., Aggarwal, R., Sirimanna, P., Moran, A., Grantcharov, T., Kneebone, R., Sevdalis, N., \& Darzi, A. (2011). Mental practice improves surgical technical skills: A controlled and randomized study. Annals of Surgery, 253(2), 265-270. https://doi.org/10.1097/SLA.obo13e318207a789

Basso, D., \& Belardinelli, M. O. (2006). The role of the feedforward paradigm in cognitive psychology. Cognitive Processing, 7(2), 73-88. https://doi.org/10.1007/s10339-006-0034-1

Bogart, D. H. (1980). Feedback, feedforward, and feedwithin: Strategic information in systems. Behavioral Science 25(4), 237-249. https://doi.org/10.1002/bs.3830250402

Bonrath, E. M., Dedy, N. J., Gordon, L. E., \& Grantcharov, T. P. (2015). Comprehensive surgical training enhances surgical skill in the operating room: A randomized controlled trial. Annals of Surgery, 262(2), 205-212. https://doi.org/10.1097/SLA.0000000000001214

Burch, N. 1970. Four stages for learning any new skill or four stages of competition. Gordon Training International.

Clapper, T. C., \& Kardong-Edgren, S. (2012). Using deliberate practice and simulation to improve nursing skills. Clinical Simulation in Nursing, 8(3), e109-e113. https://doi.org/10.1016/j.ecns.2010.12.001

Cooper, J. B., \& Taqueti, V. R. (2008). A brief history of the development of mannequin simulators for education and clinical training. Postgraduate Medical Journal, 84(997), 563-570. http://dx.doi.org/10.1136/qshc.2004.009886

Coro Montanet, G., Gómez Sánchez, M., Suárez García, A., Muñoz Leal, M. J., \& Diéguez Pérez, M. (2017). Curriculum integration of a smart virtual laboratory for skills workshops in dentistry. https://doi.org/10.26754/CINAIC.2017.000001 008

Darzi, A., Simon, S., \& Taffinder, N. (1999). Assessing operative skill needs to be more objective. (1999). British Medical Journal, 318(7188), 887-888. https://doi.org/10.1136/bmj.318.7188.887

Dave, R. H. (1970). Developing and writing behavioral goals. Educational Innovators Press.

Ericsson, K. A. (2004). Deliberate practice and acquisition and maintenance of expert performances in medicine and related fields. Academic Medicine, 79(10), s70-s81.

https://doi.org/10.1097/00001888-200410001-00022

Fann, J. I., Feins, R. H., Hicks, G. L., Nesbitt, J. C., Hammon, J. W., \& Crawford, F. A. (2012). Evaluation of training with simulation in cardiothoracic surgery: The Senior Tour perspective. Journal of Thoracic and Cardiovascular Surgery, 143(2), 264-272. https://doi.org/10.1016/j.jtcvs.2011.10.013

Fitts, P. M., \& Posner, M. I. (1967). Learning and performance specialized in human performance. Brooks/Cole.

Foley, R., \& Smilansky, J. (Eds.). (1980). Teaching techniques: A manual for health professionals. McGrawHill.

Gallagher, A. G., Ritter, E. M., Champion, H., Higgins, G., Fried, M. P., Moses, G., Smith, C. D., \& Satava, R. M. (2005). Virtual reality simulation for the operating room: Proficiency-based training as a paradigm shift in surgical skills training. Annals of Surgery, 241(2), 364-372. https://doi.org/10.1097/01.sla.0000151982.85062.80 
García-San Pedro, M. J. (2012). Feedback and feedforward: Focal points for improving academic performance. Journal of Technology and Science Education, 2(2), 77-85. https://doi.org/10.3926/jotse.49

George, E. I., Smith, R., Levy, J. S., \& Brand, T. C. (2019). Simulation in robotic surgery. In D. Stefanidis, J. R. Korndorffer Jr., \& R. Sweet (Eds.) Comprehensive Healthcare Simulation: Surgery and Surgical Subspecialties (pp. 191-220. Springer Nature. https://doi.org/10.1007/978-3-319-98276-2

Harris, J., \& Hofer, M. (2009, March). Instructional planning activity types as vehicles for curriculum-based TPACK development. In I. Gibson, R. Weber, K. McFerrin, R. Carlsen, \& D. Willis (Eds.), Proceedings of SITE 2009-Society for Information Technology \& Teacher Education International Conference (pp. 4087-4095). Association for the Advancement of Computer Science in Education (AACE). https://www.learntechlib.org/primary/p/31298/

Harrow, A. J. (1972). A taxonomy of the psychomotor domain: A guide for developing behavioral objectives. David McKay Company.

Jensen, A. R., Wright, A. S., Kim, S., Horvath, K. D., \& Calhoun, K. E. (2012). Educational feedback in the operating room: A gap between resident and faculty perceptions. American Journal of Surgery, 204(2), 248-255. https://doi.org/10.1016/j.amjsurg.2011.08.019

Leigh, G., \& Steuben, F. (2018). Setting learners up for success: Presimulation and prebriefing strategies. Teaching and Learning in Nursing, 13(3), 185-189. https://doi.org/10.1016/j.teln.2018.03.004

Lenchus, J. D. (2010). End of "see one, do one, teach one" era: The next generation of invasive bedside procedural instruction. Journal of the American Osteopathic Association, 110(6), 340-346.

Lorenzo, F. J. R., \& Porras-Gallo, M. I. (2016). Workshop protocols in clinical simulation skills (Vol. 11). University of Castilla La Mancha.

Motola, I., Devine, L. A., Chung, H. S., Sullivan, J. E., \& Issenberg, S. B. (2013). Simulation in healthcare education: A best evidence practical guide. AMEE Guide No. 82. Medical Teacher, 35(10), e1511e1530. https://doi.org/10.3109/0142159X.2013.818632

Murbay, S., Chang, J. W. W., Yeung, S., \& Neelakantan, P. (2020). Evaluation of the introduction of a dental virtual simulator on the performance of undergraduate dental students in the preclinical operative dentistry course. European Journal of Dental Education, 24(1), 5-16. https://doi.org/10.1111/eje.12453

Peyton, J. W. R. (Ed.). (1998). Teaching \& learning in medical practice. Manticore Europe Limited.

Rae, A. M., \& Cochrane, D. K. (2008). Listening to students: How to make written assessment feedback useful. Active Learning in Higher Education, 9(3), 217-230. https://doi.org/10.1177/1469787408095847

Ramaprasad, A. (1979). The role of feedback in organizational change: A review and redefinition. Cybernetica, 22(2), 105-113.

Ramaprasad, A. (1983). On the definition of feedback. Behavioral Science 28(1), 4-13. https://doi.org/10.1002/bs.3830280103

Reiley, C. E., Lin, H. C., Yuh, D. D., \& Hager, G. D. (2011). Review of methods for objective surgical skill evaluation. Surgical Endoscopy, 25(2), 356-366. https://doi.org/10.1007/s00464-010-1190-Z

Schmidt, R. A., Lee, T. D., Weinstein, C. J., Wulf, G., \& Zelaznik, H. N. (2018). Motor control and learning (6th ed.). Human Kinetics.

Shute, V. J. (2008). Focus on formative feedback. Review of Educational Research, 78(1), 153-189. https://doi.org/10.3102/0034654307313795 
Singer, R. N. (1972). Psychomotor domain: Movement behaviors. Lippincott Williams \& Wilkins.

Stefanidis, D., Anton, N. E., Howley, L. D., Bean, E., Yurco, A., Pimentel, M. E., \& Davis, C. K. (2017). Effectiveness of a comprehensive mental skills curriculum in enhancing surgical performance: Results of a randomized controlled trial. American Journal of Surgery, 213(2), 318-324. https://doi.org/10.1016/j.amjsurg.2016.10.016

Young, J. Q., Van Merrienboer, J., Durning, S., \& Ten Cate, O. (2014). Cognitive load theory: Implications for medical education: AMEE Guide No. 86. Medical Teacher, 36(5), 371-384. https://doi.org/10.3109/0142159X.2014.889290

Zafar, S., Lai, Y., Sexton, C., \& Siddiqi, A. (2020). Virtual reality as a novel educational tool in pre-clinical paediatric dentistry training: Students' perceptions. International Journal of Pediatric Dentistry, 30(6), 791-797. https://doi.org/10.1111/ipd.12648

The Higher Learning Research Communications (HLRC), is a peer-reviewed, online, interdisciplinary journal indexed in Scopus, ERIC, JGATE, and Directory of Open Access Journals (DOAJ). It is an open access journal with an international focus published by Walden University, USA. Its aim is to disseminate both high quality research and teaching best practices in tertiary education across cultures and disciplines. HLRC connects the ways research and best practice contribute to the public good and impact the communities that educators serve. HLRC articles include peer-reviewed research reports, research briefs, comprehensive literature reviews, and books reviews. 